\title{
Disability Weight Determination for Road Traffic Injuries in the Philippines: Metro Manila Scenario
}

\author{
Noel R. Juban,, ${ }^{1,2,3}$ Hilton Y. Lam,,$^{1,2,4}$ Ruzanne M. Caro, ${ }^{1,5}$ Jorge M. Concepcion, 1,6 \\ Tammy L. Dela Rosa, ${ }^{1,7}$ A'Ericson Berberabe $^{1,6}$ and Karen June P. Dumlao ${ }^{1,8}$ \\ ${ }^{1}$ The Philippine DALYs Study Group, College of Medicine, University of the Philippines Manila \\ ${ }^{2}$ Department of Clinical Epidemiology, College of Medicine, University of the Philippines Manila \\ ${ }^{3}$ Institute of Clinical Epidemiology, National Institutes of Health, University of the Philippines Manila \\ ${ }^{4}$ Institute of Health Policy and Development Studies, National Institutes of Health, University of the Philippines Manila \\ ${ }^{5}$ Department of Otorhinolaryngology and College of Medicine and Philippine General Hospital, University of the Philippines Manila \\ ${ }^{6}$ Department of Emergency Medical Services, College of Medicine and Philippine General Hospital, University of the Philippines Manila \\ ${ }^{7}$ Department of Orthopedics, College of Medicine and Philippine General Hospital, University of the Philippines Manila \\ ${ }^{8}$ Department of Anatomy, College of Medicine, University of the Philippines Manila
}

\begin{abstract}
Objective. To determine the Disability Adjusted Life Year (DALY) weights of road traffic injuries and use the DALY weights in determining the total DALYs lost in Metro Manila using available data.

Methods. Consensus on DALY weights for each of the 31 International Classification of Diseases (ICD)10 codes related to road traffic injuries was done using Delphi Process. Experts from different fields were invited to participate in 2 rounds of discussion-and-scoring were done to obtain consensus were obtained for each DALY weight. Philippine Health Insurance Corporation (PHIC) data on the counts of the 31 ICD 10 coded claims for the years 2011, 2012, and 2013 were obtained and used to calculate the total DALY lost due to vehicular injuries for Metro-Manila.

Results. Road traffic related injuries affected mostly young people (mean 34 yo +15$)$ and affected mostly men (81\%). There were a total of 3,199 injuries seen in 2,573 patients. $98.1 \%$ of the patients had a $<1$ year type of injury with an average disability weight of 0.34154 and a total DALYs lost of 300.4 . $0.5 \%$ of the patients had $a \geq 1$ year type of injury with an average disability weight of 0.2726 and a total DALYs lost of $218.08 .1 .4 \%$ of the patients most likely died from their injuries earning a total DALYs lost of 1,440.The sum of DALYs lost is equivalent to a total of 1,958.12.

Conclusion. The Metro Manila loses roughly Php 76.6 Million per year due to road traffic injuries and accidents. These events are highly preventable. Without proper interventions, road traffic injuries may lead to impoverishment of the young families who pick up the pieces, or are left behind.
\end{abstract}

Key Words: DALY, quality of life, road traffic injury, years of life lost, years lost to disability, Delphi method

\section{INTRODUCTION}

Presented during the First ASEAN Patient Safety Congress, June 25-26, 2015,Sofitel Philippine Plaza Manila.

Corresponding author: Noel R. Juban, MD, MSc in Epidemiology Department of Clinical Epidemiology

College of Medicine, University of the Philippines Manila

Pedro Gil Street, Ermita Manila 1000, Philippines

Telefax: +6325254098

Email: noeljbn@yahoo.com,drnoelj@gmail.com
According to the World Health Organization (WHO), road traffic accidents are the fifth leading cause of burden of disease in the Western Pacific Region and the fourth in middle-income countries in 2004. ${ }^{1}$ There is a noted plateau of the number of road traffic injuries since 2007, which stands at 1.25 million in 2013. This may be attributed to the interventions on global road safety implemented in the last few years. This occurrence has been documented despite the global population and motorization increase. ${ }^{2}$

Based on a systematic review of articles over 35 years, road traffic accidents accounted for $15 \%$ of all injury 
deaths and were found to increase by $600 \%$ from 1960 to 1995. Moreover, it emphasized the need for improvements on injury surveillance and documentation of non-fatal injury outcomes. ${ }^{3}$

Several data suggest that despite this steady state, low to middle income countries, reflect unfavorable trends on road traffic injuries. There are more than twice the percentages of fatalities for low - income countries compared to high income countries. Even if low to middle income countries only have $54 \%$ of the world's vehicles, around $90 \%$ of deaths occur in them. ${ }^{2}$ Furthermore, due to the projected economic growth of low-middle income countries, such as the Philippines, and resultant increase in motor vehicle ownership, deaths due to road traffic accidents are expected to increase from 1.3 million in 2004 to 2.4 million in $2030 .{ }^{1}$

The Department of Health (DOH) reported accidents as the fifth leading cause of mortality in the whole population ${ }^{4}$ and the fourth leading cause of mortality in children aged 10 to 14 years in $2010 .^{5}$

The Department of Public Works and Highways, in coordination and partnership of other private and international agencies is responsible for transport evaluation, and implementation of road development and safety. Responsibility for the maintenance of the National Roads are given to them while the local roads are under the supervision of the different local government units. ${ }^{6}$

An increase in the number of different modes of road transport can be seen in Metro Manila which would lead to a delay in traffic and affecting the different sectors of the country. This is mainly due to the inefficient regulation of public transport vehicles accompanied with substandard enforcement of traffic laws. ${ }^{6}$ The rise in the number of vehicles leading to road congestion accompanied with minimal improvement on road structures play a role in the development of road traffic injuries in lower-middle income countries. ${ }^{7}$

Health status has become one of the important outcome measurements in the evaluation of medical interventions, in addition to the more traditionally used outcome of mortality. ${ }^{8}$ Disability-adjusted life years (DALYs) in burden of disease and injury studies have been developed by the World Health Organization to measure the quality of life of the population by combining information on the impact of premature death, disability and other non-fatal health outcomes. ${ }^{9}$
The disability-adjusted life-year (DALY) is an indicator that combines the years of life lost from early death (YLL) and the years of life lost due to disability (estimated from the years lived with disability (YLD) (Figure 1). It can identify which diseases and injuries have the greatest health loss which can be used to guide policymakers in prioritizing health programs.

By representing the quality of life of a population as a mathematical equation, the method is standardized, allowing comparison of the data over a period of time and even between different populations. ${ }^{10}$ DALYs are considered more advanced over other composite indicators, such as quality adjusted life years because the value choices are made explicit and thus open to scrutiny and influence. It has become the standard outcome measure in public health and the primary outcome for priority-setting in health care and prevention. ${ }^{11}$

While the World Health Organization (WHO) has provided global disability weights to compute for DALYs for various regions, it may not necessarily reflect the socio-economic impact of disease and injury in the Philippine setting. Consideration of the unique socioeconomic milieu will lessen underestimation of the burden associated with disadvantaged populations. It will also lessen overestimation of the burdens among more advantaged populations..$^{10}$ However, some studies suggest that they do not factor socioeconomic status, access to health care, environmental barriers and coping strategies in computing for disability weights. ${ }^{12}$

This study aims to provide local specific DALYs for road traffic injuries in Metro Manila using the Delphi Process based on available data by identifying, discussing and ranking the specific health states resulting from road traffic injuries included in this study.

\section{METHODS}

This study was submitted to and approved by the University of the Philippines Research Ethics Board prior to its implementation.

Experts coming from different multidisciplinary sections were invited to participate in the Delphi method (Table 1). Purposive sampling was done in the determination of participants from each field. Due to the difficulty in getting

$$
\begin{aligned}
& \text { DALY in an individual is computed using the formula: } \\
& \text { DALY = YLL + YLD } \\
& \text { YLL is computed using the formula: } \\
& \text { YLL = maximum age - age of death } \\
& \text { YLD is computed using the following: } \\
& \text { YLD = (disability severity weight) } \times \text { (average time a person is suffering from the disability / the disease) }
\end{aligned}
$$

Figure 1. Formula for the computation of DALYS.

DALY, Disability Adjusted Life Years; YLL, Years Life Lost; YLD, Years Lived with Disability. 
Table 1. List of the Different Specialties Invited to Participate in the Delphi Process

Burn
Emergency Medicine
ENT
Epidemiology
Family Medicine
Highschool Teacher
HMO industry
Human Resources Management
Internal Medicine
Medico legal
Neurosurgery
Nursing
Obstetrics and Gynecology
Occupational Therapy

all the participants in one venue at one particular time, we decided to do multiple small group meetings with different participants. The Delphi method were done from June to November 2014 on the following specific dates: (1) June 19, 2014 at the Center for Community Oriented Medical Education, 1st floor, Paz Mendoza Building, UP Manila College of Medicine with participants from the following fields: Orthopedic Surgery, Pediatrics, Emergency Medicine ENT, Ophthalmology, Rehabilitation Medicine, Physical Therapy, Occupational Therapy, Nursing, Highschool teacher, Social Worker, Epidemiologist; (2) August 15, 2014 at the Alumni Hall Conference Room, $1^{\text {st }}$ floor, Paz Mendoza Memorial Building, UP Manila College of Medicine with the following participants: Medico-legal, Psychiatry, Family Medicine, Burn, Internal Medicine and (3) November 28, 2014 at the Research Implementation and Development Office Conference Room, $2^{\text {nd }}$ floor, Paz Mendoza Memorial Building, UP Manila College of Medicine with participants from the following fields: Human resources management, obstetrics and gynecology, Religious sector, orthopedic patient, social security system, traffic expert.

English was the primary language used in all the materials and during the discussions with some participants using the Filipino language. No translation to Filipino or Filipino to English was needed.

The Delphi method is a technique designed to elicit opinions form a group to generate a group response. Delphi replaces direct confrontation and debate by a carefully planned, anonymous, orderly program of sequential individual interrogations usually conducted by questionnaires. ${ }^{13}$ The process takes 2 or more 'rounds' in which the second and later rounds of the survey are given as feedback. Content of Delphi studies are always issues about which incomplete knowledge exists. As a kind of consensus development method, the Delphi technique offers a practical means of arriving to a consensus using a relatively small number of people who can participate.

Informed consent for the participation in the study was obtained before the Delphi processes began.
The list of conditions for disability weighting was taken from Disability weights for diseases: A modified protocol and results for a Western European region (2000). European Journal of Public Health and Internal Classification of Diseases tenth edition (ICD 10).

The effects of illness and injuries are captured through disability classes that were assigned increasing weight associated with the extent of loss of physical functioning. ${ }^{14}$ Weights of the six classes have been chosen by a group of independent experts.

The disability weight is a measure of the impact of a health condition and its calculation is based on the preferences of a panel of experts for each health state relative to full health and to death. ${ }^{10}$ It is a value ranging from 1 , indicating the worst imaginable health state, to 0 , indicating full health. It quantifies the societal preferences for health states in relation to the societal 'ideal' of good health. ${ }^{15}$

Disability weighting was based on the Visual Analog Scale (VAS) valuation method. Participants were asked to rate each disease by marking its place in his or her opinion on the VAS sheet that was provided. There were no strict guidelines in assigning weights. However, participants were encouraged to give their opinions on how they arrived at their VAS scores. Selection of one VAS score to represent the disability weight of a particular disease was done using the Delphi method.

For the first round of discussion, the panel was asked to discuss the VAS score they gave for each condition based on their field of expertise. After all the participants have discussed their scores, they were asked to rescore all the conditions based on the things they learned and heard from the other participants during the discussion. After the second round, the panel was asked to discuss again the scores they gave and the reasons they changed their scores.

The VAS scores from the panel session were converted into weights using the formula. (Figure 2) ) $^{16,17}$

$$
\text { DALY Weight }=\frac{\text { Average VAS Score } \mathrm{Q}}{\mathrm{Q}^{*} \text { incidents }}
$$

where Average VAS score $=$ the mean score for each ICD10 code obtained through the Delphi rounds;

$\mathrm{Q}=$ condition as represented by the ICD10 code, and

Incidents = total counts in the PHIC dataset of that specific ICD10 code or condition.

Figure 1. Formula for the computation of disability weights. ${ }^{16,17}$

VAS, Visual Analog Scale; PHIC, Philippine Health Insurance Corporation; ICD 10, International Classification of Diseases tenth edition.

\section{Data processing and analysis}

The panel determined VAS scores for every indicator condition at the end of the deliberation process using the Delphi method. The VAS scores were encoded into MS Excel (Microsoft Office Professional Plus 2013). Disability weights were computed using the formula above using MS 
Excel. Interpolation was done by the panel based on the computed disability weights. The interpolated disability weights were encoded into MS Excel.

A dataset of admissions related to road injuries (diagnosis contains ICD10 code V00 to V89) in accredited hospitals in Metro Manila from Calendar Year (CY) 2011-
2013 were obtained from the Philippine Health Insurance Corporation (PHIC). The following variables were requested: age, sex, admission period, and illness ICD codes. The dataset was cleaned using Microsoft Excel. However, out of the 60 indicator condition from the list, only 28 ICD-10 codes were found in the PHIC data (Table 2).

Table 2. Range of Disability Weights for each of the ICD-10 Codes

\begin{tabular}{|c|c|c|c|c|c|}
\hline ICD Code & Description & $\begin{array}{l}\text { Disability } \\
\text { Weight } \\
\text { (Philippines) }\end{array}$ & ICD Code & Description & $\begin{array}{l}\text { Disability } \\
\text { Weight } \\
\text { (Philippines) }\end{array}$ \\
\hline \multirow[t]{2}{*}{ Death } & \multirow[t]{2}{*}{ Loss of Life within 30 days } & \multirow{2}{*}{$\begin{array}{l}\text { 1.0 DALY } \\
\text { per year of } \\
\text { life lost }\end{array}$} & $\mathrm{H} 54.2$ & \multirow{2}{*}{$\begin{array}{l}\text { Distance vision: moderate impairment } \\
\text { Fracture other than neck of femur: } \\
\text { short term, with or without treatment }\end{array}$} & 0.326 \\
\hline & & & S72.0 & & 0.324 \\
\hline \multirow{2}{*}{$\begin{array}{l}\text { S14.0 } \\
\text { S14.0 }\end{array}$} & \multirow{2}{*}{$\begin{array}{l}\text { Spinal cord lesion at neck level; untreated } \\
\text { Spinal cord lesion at neck level; treated }\end{array}$} & 0.798 & \multirow[t]{2}{*}{$\mathrm{S} 72$} & \multirow{2}{*}{$\begin{array}{l}\text { Fracture other than neck of femur: } \\
\text { long term, without treatment }\end{array}$} & \multirow[t]{2}{*}{0.320} \\
\hline & & 0.694 & & & \\
\hline \multirow[t]{2}{*}{ S58.9 } & \multirow{2}{*}{$\begin{array}{l}\text { Amputation of both arms: } \\
\text { long term, without treatment }\end{array}$} & \multirow[t]{2}{*}{0.665} & S32 & Fracture of Vertebral column & 0.315 \\
\hline & & & $\mathrm{S} 22.3$ & Fracture of Rib or sternum & 0.313 \\
\hline F43.1 & Post Traumatic Stress Disorder & 0.658 & S54 & Injured nerves: long term & 0.313 \\
\hline H54.0 & Distance vision blindness & 0.645 & S52 & Fracture of Radius or ulna, & 0.312 \\
\hline \multirow[t]{2}{*}{$\mathrm{S} 88$} & Amputation of both legs: & \multirow[t]{2}{*}{0.634} & & with treatment & \\
\hline & long term, without treatment & & S28.0 & Severe Chest Injury & 0.306 \\
\hline S34 & Spinal cord lesion below neck; untreated & 0.632 & S82 & Fracture of Patella, tibia, or & 0.306 \\
\hline H91.93 & Hearing loss, complete & 0.601 & & fibula, or ankle: long term, & \\
\hline \multirow[t]{3}{*}{ S06.2X9D } & Traumatic brain injury: & 0.594 & \multirow{4}{*}{$\begin{array}{l}\mathrm{S} 02 \\
\mathrm{~S} 68.1\end{array}$} & \multirow{4}{*}{$\begin{array}{l}\text { with or without treatment } \\
\text { Fracture of Skull: short-term or long term } \\
\text { Amputation of finger(s), excluding } \\
\text { thumb: long term, with treatment }\end{array}$} & \multirow{4}{*}{$\begin{array}{l}0.305 \\
0.303\end{array}$} \\
\hline & long term consequences, severe, & & & & \\
\hline & with or without treatment & & & & \\
\hline H91.93 & Hearing loss, profound & 0.530 & & & \\
\hline \multirow[t]{2}{*}{ T30.0 } & \multirow{2}{*}{$\begin{array}{l}\text { Burns of } \geq 20 \% \text { total surface area or } \\
\geq 10 \% \text { total surface area of head or neck, } \\
\text { or hands or wrist involved: long term }\end{array}$} & \multirow[t]{2}{*}{0.530} & S43006A & $\begin{array}{l}\text { Dislocation of shoulder: long term, } \\
\text { with or without treatment }\end{array}$ & 0.3 \\
\hline & & & S28.0XXA & $\begin{array}{l}\text { Severe chest injury: long term, } \\
\text { with or without treatment }\end{array}$ & 0.3 \\
\hline \multirow{2}{*}{ S06.2X9D } & long term consequences, moderate, & \multirow{2}{*}{0.490} & S68.02 & Amputation of thumb: long term & 0.289 \\
\hline & with or without treatment & & S62.90XS & Fracture of Hand bones, long term & 0.286 \\
\hline \multirow{3}{*}{$\begin{array}{c}\mathrm{H} 54.2 \\
\mathrm{~S} 07\end{array}$} & Distance vision: severe impairment & 0.487 & \multirow[t]{2}{*}{ S83 } & Dislocation or knee: long term, & 0.284 \\
\hline & Crush injury: short or long term, & 0.473 & & with or without treatment & \\
\hline & with or without treatment & & S02.9 & Fracture of facial bones & 0.275 \\
\hline S58.9 & $\begin{array}{l}\text { Amputation of one arm: long term, } \\
\text { with or without treatment }\end{array}$ & 0.455 & S62.90XS & $\begin{array}{c}\text { Fracture of Hand bones, short term, } \\
\text { with or without treatment }\end{array}$ & 0.272 \\
\hline S88 & $\begin{array}{l}\text { Amputation of one leg: } \\
\text { long term, without treatment }\end{array}$ & 0.444 & T30.0 & $\begin{array}{c}\text { Burns of }<20 \% \text { total surface area or } \\
<10 \% \text { total surface area of head or neck, }\end{array}$ & 0.263 \\
\hline T30.0 & Burns of $\geq 20 \%$ total surface area: & 0.436 & & or hands or wrist involved: long term & \\
\hline & short term & & S42.009A & Clavicle, scapula or humerus & 0.262 \\
\hline S06.307A & Severe traumatic brain injury: & 0.434 & H91.93 & Hearing loss, moderate & 0.256 \\
\hline & short term, with or without treatment & & S54 & Injured nerves, short term & 0.248 \\
\hline S14.1 & Spinal cord lesion below neck; treated & 0.426 & S92.909S & Fracture of foot bones: short-term, & 0.237 \\
\hline S32 & Fracture of Pelvis, long term & 0.407 & & with or without treatment & \\
\hline S06 & $\begin{array}{l}\text { Traumatic brain injury: } \\
\text { long term consequences, minor, }\end{array}$ & 0.406 & S88 & $\begin{array}{l}\text { Amputation of one leg: } \\
\text { long term, with treatment }\end{array}$ & 0.226 \\
\hline S32 & $\begin{array}{l}\text { with or without treatment } \\
\text { Fracture of Pelvis, short term }\end{array}$ & 0.396 & S73 & $\begin{array}{l}\text { Fracture of hip: long term, } \\
\text { with or without treatment }\end{array}$ & 0.225 \\
\hline H91.93 & Hearing loss, severe & 0.393 & T30.0 & Burns of $<20 \%$ total surface area & 0.198 \\
\hline S88 & Amputation of both legs: & 0.377 & & without lower airway burns: short term & \\
\hline & long term, with treatment & & S54 & Other injuries of muscle and tendon & 0.197 \\
\hline S28.0XXA & $\begin{array}{l}\text { Severe chest injury: short term, } \\
\text { with or without treatment }\end{array}$ & 0.376 & & $\begin{array}{l}\text { (includes sprains, strains, and dislocations } \\
\text { other than shoulder, knee, or hip) }\end{array}$ & \\
\hline S52 & Fracture of radius or ulna, & 0.354 & S98.1 & Amputation of toe & 0.168 \\
\hline & without treatment & & $\mathrm{H} 54.2$ & Distance vision: mild impairment & 0.168 \\
\hline S58.9 & Amputation of both arms: & 0.339 & H91.93 & Hearing loss, mild & 0.166 \\
\hline S05 & $\begin{array}{l}\text { long term, with treatment } \\
\text { Injury to eyes: short term }\end{array}$ & 0.33 & T14.8 & $\begin{array}{l}\text { Open wound: short term, } \\
\text { with or without treatment }\end{array}$ & 0.136 \\
\hline S82 & $\begin{array}{l}\text { Patella, tibia, or fibula, or ankle: } \\
\text { short term, with or without treatment }\end{array}$ & 0.328 & & nal Classification of Diseases & \\
\hline
\end{tabular}




\section{RESULTS AND DISCUSSION}

Out of 5139 patients hospitalized in the PHIC data from CY 2011-2013, 2,573 patients were classified under the ICD-10 codes from our list. The data consists of a total of 5,139 patients comprised of 3,119 patients from government institutions ( 1 patient from a government infirmary/dispensary, 120 patients from primary hospitals, 68 patient from secondary hospitals and 2,930 patients from tertiary hospitals) and 2,020 patients from private institutions (1 patient from an ambulatory/surgical clinic, 119 patients from primary hospitals, 371 patients from secondary hospitals and 1,529 patients from tertiary hospitals).

Road traffic related injuries affected mostly young people (mean 34 yo \pm 15 ) and affected mostly men (81\%). With an average life expectancy of 71 years old for Filipinos, ${ }^{18}$ the total DALYs lost for injuries of $<1$ year, $\geq 1$ year and injuries resulting to death were computed.

The biggest disability weight of 0.798 was given to an injury of the spine at the neck level without any treatment followed by the 0.694 for an injury of the spine at the neck level with treatment. While the 2 conditions given the lowest disability weight were given to a mild hearing loss (0.166) and open wound (0.136).

The percentage of DALYs from injuries has remained stable from $10 \%$ in 1990 to $11 \%$ in 2010 . The largest component among the DALYs from injuries is the due to road traffic injuries comprising $27 \%$. Vehicular crashes, termed road traffic injury in the 2010 Global Burden of Disease (GBD) study, accounted for 75.5 million DALYs. Injuries affect mostly young people, often causing longterm disability. ${ }^{19}$ Most causes of road traffic injuries are said to be preventable and many effective strategies to reduce this problem are available. Thus, the 2010 GBD study calls for continued initiatives to address this problem. ${ }^{20}$
Majority of deaths and DALYs caused by road injuries in lower middle-income countries in 2002 were observed, accounting for $34 \%$ and $28 \%$ respectively. ${ }^{7}$

A retrospective study done in Honiara, Solomon Islands which focused on the extent, causes and impact of road traffic accidents revealed that road traffic crashes were predominantly male $(73 \%)$ and were between the ages of $10-29(48 \%){ }^{21}$

When compared to a high-income country such as France, it showed some similarities with the results of this study. A study pertaining to the burden of road traffic accidents done in France showed high YLD and YLL in the 15-24 years age bracket. Furthermore, the highest disability weight was given to spinal cord injury $(0.725)$ while the lowest disability weight was given to sprains $(0.064) .{ }^{22}$ The study used a compatibility table listing the similarities of the ICD10 codes with the AIS90 codes.

There were a total of 3,199 injuries seen in 2,573 patients. $98.1 \%$ of the patients had a $<1$ year type of injury with an average disability weight of 0.34154 and a total DALYs lost of 300.4. Less than one percent (0.5\%) of the patients had $\mathrm{a} \geq 1$ year type of injury with an average disability weight of 0.2726 and a total DALYs lost of 218.08. The PHIC data did not show the outcomes on discharge. Of all these patients, $1.4 \%$ most likely died from their injuries earning a total DALYs lost of 1,440 (Table 3).

In 2,573 patients, we noted 3,199 number of injuries. Of the patients with $a<1$ year type of injury, there is a ratio of 1 patient : 1.2 injuries and for those with a $\geq 1$ year type of injury, there is a ratio of 1 patient: 1.7 injuries (Table 4).

The disability weights from the GBD Study have been touted to have a 'strong egalitarian flavor' by its global, fixed context. However, some health scientists argue that by ignoring social, cultural, or environmental context of the condition the realities of the burden of disease cannot be

Table 3. Dimensions of Disability

\begin{tabular}{cccccc} 
Dimensions of & \multicolumn{4}{c}{ DALYs } \\
Disability & No. of patients & No. of injuries & Metro Manila (2,573 hospitalized victims) & Total \# of years & Total DALYs lost \\
\cline { 2 - 6 } < 1 year & 2,525 & 3,143 & 0.34154 & 0.2795 & 300.04 \\
$\geq 1$ year & 12 & 20 & 0.2726 & 40 & 218.08 \\
Death & 36 & 36 & 1 & 40 & $1,440.00$ \\
\hline Totals & 2,573 & 3,199 & & $1,958.12$ \\
\hline
\end{tabular}

DALY, Disability Adjusted Life Year

Table 4. Distribution of Severity

\begin{tabular}{|c|c|c|c|c|c|c|}
\hline \multirow{2}{*}{$\begin{array}{l}\text { Distribution of } \\
\text { Severity }\end{array}$} & \multicolumn{6}{|c|}{$\begin{array}{c}\text { DALYs } \\
\text { Metro Manila (2,573 hospitalized victims) }\end{array}$} \\
\hline & No. of patients & $\%$ & No. of injuries & $\%$ & Total DALYs lost & $\%$ \\
\hline$<1$ year & 2,525 & $98.1 \%$ & 3,143 & $98.24 \%$ & 300.04 & $15 \%$ \\
\hline$\geq 1$ year & 12 & $0.5 \%$ & 20 & $0.63 \%$ & 218.08 & $11 \%$ \\
\hline Death & 36 & $1.4 \%$ & 36 & $1.13 \%$ & $1,440.00$ & $74 \%$ \\
\hline Totals & 2,573 & $100 \%$ & 3,199 & $100 \%$ & 1958.12 & $100 \%$ \\
\hline
\end{tabular}

DALY, Disability Adjusted Life Year 
clearly established. Some traditional societies that stigmatize and reject individuals with specific permanent impairments. Governments provide varying degrees of support for people of disabilities. For example, paraplegics in Australia have more access to wheelchairs as opposed to those in Cameroon. Australian building codes provide for equity of access to persons with disability where wheelchairs may be a useful intervention. The burden of disease measured by DALYs do not reflect the individuals' differential ability to cope with their functional limitation. ${ }^{23}$ This ability is heavily influenced by the society in which the person with disability lives. Studies which estimate disability weights on a national level could estimate the national injury burden more reliably than utilizing those published in the GBD study. ${ }^{19}$

The sum of DALYs lost is equivalent to a total of 1,958.12. Taking into consideration the 2013 Gross Domestic Product (GDP) per capita of Php 117, 374.25, ${ }^{18}$ and total GDP of NCR which is $36.3 \%$ of the National GDP (Php 4,162,859,941,086.00) $)^{24}$ total economic equivalent of the DALYs lost is PhP 229.8 Million (in 3 years) which is roughly a minimum Php 76.6 Million per year in Metro Manila representing $0.0055 \%$ of the GDP of NCR. This represents the lowest value of injuries in NCR but it can be higher than the computed value because the GDP per capita approximates only the minimum wage in the Philippines so that a person earning more than the minimum wage will lose more. In a report from the Developmental Bank of the Philippines (DBM), it was indicated in the Statement of Receipts and expenditures, By Cities, 2013, that the total expenditure of NCR is Php 63,321,170,000.00 while the revenues amounted to $\mathrm{Php} 111,161,600,000.00$ which leaves a balance of Php 47,840,430,000.00. ${ }^{16} \mathrm{Php} 76.6 \mathrm{M}$ is only $0.12 \%$ of the total NCR expenditure. NCR could have allotted the surplus for the prevention of RTIs.

The main purpose of the study is to determine the DALYs which was done on primary data. The second part of the study is projection of the consensus on a physical data, but for this study, secondary data was used. Hence, the limitations would include: inherent errors in data set and limited scope of the data set (only PHIC accredited hospitals and patients were used in the report). We used the National GDP per capita which reflects only the minimum productivity of a resident so that if an RTI victim earns more than the minimum wage, then our study would be underreporting. But at the same time, we give the minimum amount for an unemployed resident, in that case, it would be over reporting. Since this study is designed to identify the minimum burden, we found it just to use the average or the GDP per capita.

The average economic losses due to road traffic injuries in developing countries was found to be equivalent to $1 \%$ of the GDP in $2000 .{ }^{7}$ In 2005, the assessment on the cost of road accidents in the Philippines was equal to $2.8 \%$ of the nation's GDP. ${ }^{6}$ Other lower middle income countries like Vietnam was estimated to have losses due to road traffic injuries equivalent to $2.45 \%$ of their GDP in the same year. ${ }^{25}$
Methodologically, the Delphi method is very efficient in its process. ${ }^{26}$ This is due mainly to the practical nature of the Delphi method especially in its facilitation. It must be noted that in the selection of participants, it is important that they represent the target audience for the output. In this particular study, persons whose work are connected to vehicular accidents related disabilities. "In practice, given the multiprofessional or multidisciplinary nature of most health care activities, it is advisable to ensure that all relevant professional or stakeholder groups are represented". ${ }^{26}$ Another reason for utilizing this kind of consensus development method is it takes into consideration the potential chronically ill individuals' ability to cope. Underestimation of disease burden results from the ability to adapt. ${ }^{12}$

Although there are many cases that the Delphi process has proved to be effective and efficient, it is still important that a way to standardize results be established to eliminate bias. Questionnaires and data collection tools are used to maintain reliability of results. Rules in facilitating are established as well so that each round of the Delphi process will not interfere with the credibility of the results. ${ }^{27}$

\section{CONCLUSION}

Road traffic injuries occur due to several factors but mainly due to poor implementation of traffic safety and failure to regulate public transport. As a result, people from the work force are mainly affected leading to an economic loss of roughly Php 76.6 million per year. The creation of local data on DALYs and disability weights has provided insight on the current situation of the country and can be used to generate possible health policies in the future.

\section{Acknowledgments}

This study was made possible by an unrestricted grant from the Patient Safety Program of the UP College of Medicine and the dataset from the Philippine Health Insurance Company.

\section{Statement of Authorship}

All authors approved the final version submitted.

\section{Author Disclosure}

All authors declared no conflicts of interest.

\section{Funding Source}

This paper was funded by the College of Medicine, University of the Philippines Manila.

\section{REFERENCES}

1. World Health Organization. The Global Burden of Disease 2004 Update [Online]. 2008. [cited 2013 April]. Available from http://www. who.int/healthinfo/global_burden_disease/2004_report_update/en/ index.html 
2. WHO. Global Status Report on Road [Online]. 2013 [cited 2015 May].Available from http://www.who.int/violence_injury_prevention/ road_safety_status/2013/en/index.html

3. Consunji RJ, Hyder AA. The burden of injuries in the Philippines: implications for national research policy. Accid Anal Prev. 2004 Nov; 36(6):1111-7.

4. Department of Health. Leading Causes of Mortality [Online]. 2010 [cited 2014 July]. Available from http://www.doh.gov.ph/node/2573.

5. Department of Health. Leading Causes of Child Mortality [Online]. 2010. Available from http://www.doh.gov.ph/node/1488

6. Asian Development Bank. Philippines: Transport Sector Assessment, Strategy, and Road Map. 2012;18.

7. Norton R, Hyder A, Bishai D, Peden M. Chapter 39: Unintentional Injuries. Dis Control Priorities Dev Ctries. 2006; 737-53.

8. Krabbe PFM, Essink-Bot MD, Bonsel GJ. On the equivalence of collectively and individually collected responses: Standard gamble and time-trade-off judgments of health states. Med Decis Making. 1999; 16:120-132.

9. Brennan DS, Spencer AJ. Disability weights for the burden of oral disease in South Australia. Popul Health Metr. 2004; 2:7 doi: 10.1186/1478-7954-2-7pmid: 15345059

10. Reidpath DD, Allotey PA, Kouame A, Cummins RA. Measuring health in a vacuum: examining the disability weight of the DALY. Health Policy Plan. 2003 Dec; 18(4):351-6.

11. Haagsma JA. Disability adjusted life years and acute onset disorders: Improving estimates of the non-fatal burden of injuries and infectious intestinal disease. Rotterdam: Erasmus University, 2010.

12. Gabbe BJ, Lyons RA, Simpson PM, Rivara FP, Ameratunga S, Polinder S, et al. Disability weights based on patient-reported data from a multinational injury cohort. Bull World Health Organ. 2016; 94(11):806-816C.

13. Brown B, Cochran S, Dalkey N. The Delphi method, II: Structure of experiments, Santa Monica, California: Rand Corporation, 1969.

14. Murray CJL, Lopez AD (Eds.) The global burden of disease: A comprehensive assessment of mortality and disability from diseases, injuries and risk factors in 1990 and projected to 2020. Boston: World Health Organization, 1996.

15. Mathers CD, Vos ET, Stevenson CE, Begg SJ. The burden of disease and injury in Australia. Bull World Health Organ. 2001; 79(11):1076-84.
16. Murray CJL, Ezzati M, Flaxman AD, et al. GBD 2010: a multiinvestigator collaboration for global comparative descriptive epidemiology. The Lancet. 2012 Dec; 380(9859):2055-8.

17. The International Bank for Reconstruction and Development / The World Bank. World development report 1993: Investing in health. Washington, DC: Oxford University Press, 1993.

18. Philippine Statistics Office. Life expectancy at birth [Online]. 2000 [cited 2016 Aug]. Available from http://www.nscb.gov.ph/secstat/d_ popnProj.asp

19. Lim D, Lee WK, Park H. Disability-Adjusted Life Years (DALYs) for Injuries Using Death Certificates and Hospital Discharge Survey by the Korean Burden of Disease Study 2012. J Korean Med Sci. 2016; 31:S200-207.

20. Krug EG, Sharma GK, Lozano, R. The global burden of injuries. Am J Public Health. 2000; 90:523-6.

21. Stewart MJ, Negin J, Farrell P, Houasia P, Munamua AB, Martiniuk A. Extent, causes and impact of road traffic crashes in the Solomon Islands 1993-2012: Data from the orthopaedic department at the National Referral Hospital, Honiara. Rural Remote Health. 2015; 15(3):2945

22. Lapostolle A, Gadegbeku B, Ndiaye A, Amoros E, Chiron M, Spira A, et al. The burden of road traffic accidents in a French Department: the description of the injuries and recent changes. BMC Public Health. 2009; 9(1):386.

23. Anand S, Hanson K. Disability-adjusted life years: a critical review. J Health Econ. 1997; 16:685-702.

24. Business Mirror. Metro Manila per-capita GDP increased to P203,132 in 2014. [Online] 2015. [cited 2017 July]. Available from http:// www.businessmirror.com.ph/metro-manila-per-capita-gdp-increasedto-p203132-in-2014/

25. Bachani AM, Branchini C, Ear C, et al. Trends in prevalence, knowledge, attitudes, and practices of helmet use in Cambodia: results from a two year study. Injury. 2013; 44 Suppl 4:S31-7.

26. Black N. Consensus development methods. In: Pope C, Mays N, eds. Qualitative Research in Health Care. Blackwell Publishing; 2006. pp. $132-133$.

27. Jones C. The Delphi Method: A Delphi Evaluation Agreement Between Organizations. p.115. 